\title{
Exergy Analysis of a Brine Mixing Once - Through MSF-BM Distillation Plant
}

\author{
Usama Ahmed Ezzeghni ${ }^{1 *}$, Mohamed Abduljawad ${ }^{2}$ \\ ${ }^{1}$ Department of Desalination Researches, Nuclear Research Center, Libya \\ ${ }^{2}$ Department of Scientific Publications Authority of Natural Sciences, Research and Technology, \\ Libya \\ DOI: https://doi.org/10.21467/proceedings.4.36 \\ * Corresponding author email: elzoghni@gmail.com
}

\begin{abstract}
Exergy analysis is a tool that can be used to detect the sites and causes of thermodynamic inefficiencies in a thermal process, as well as to prospect the design performance of any industry plants. The practice of such an analysis in seawater desalination plants is of increasing importance to discover the sites of the biggest irreversible losses. In this paper a full exergy analysis of a brine mixing once through multi stage flash MSF-BM desalination plant was carried out to identify the component that has the largest exergy destruction. The MSF-BM desalination plant is located at $30 \mathrm{~km}$ north-west of Tripoli the capital of Libya.

Exergy flow rates are estimated all over the plant and exergy flow diagram is prepared. The results of the exergy analysis show that the multi-stage flash unit, pumps and motors are the major sites of highest exergy destruction, where $61.48 \%$ of the entire input exergy took place in the MSF unit, and $19.8 \%$ happens in the pumps and motors. The second law of efficiency was estimated to be $6.24 \%$, which seems to be low that mean some improvements should be made to improve the plant efficiency and reduce exergy destruction, the improvement can be made to the MSF unit by increasing the number of flashing stages and to the pumps and motors by installing modern pumps with high efficiency.
\end{abstract}

Keywords: seawater desalination; exergy; exergy flow rates, exergy analysis.

\section{Introduction}

The leading desalination approaches used are multi-stage flash distillation (MSF), which establishes $44 \%$ of installed world capacity, and reverse osmosis (RO) with constitutes $42 \%$ that also comprises nanofiltration (NF). Consequently, these two approaches create about $86 \%$ of total world capacity. The outstanding $14 \%$ is made up of electrodialysis (EDR) (6\%), vapor compression (VC) (4\%), and multiple-effect distillation (ME) (4\%) [1]. Even if these techniques are well established, there is a necessity to push the state of the art forward to make the operation of these plants more effective. An evaluation of the idealized and actual

(C) 2018 Copyright held by the author(s). Published by AIJR Publisher in Proceedings of First Conference for Engineering

Sciences and Technology (CEST-2018), September 25-27, 2018, vol. 2 .
This is an open access article under Creative Commons Attribution-NonCommercial 4.0 International (CC BY-NC 4.0)

Ai license, which permits any non-commercial use, distribution, adaptation, and reproduction in any medium, as long as the original work is properly cited. ISBN: 978-81-936820-6-7 
desalination technologies displays that the actual energy cost of desalination is around 5-10 times the cost under ideal operation. This matches to a second law efficiency of under $20 \%$ and points out that there are good chances in the MSF plants for improvements. The initial step in any upgrading or development project is diagnostics, and the dominant diagnostics tool in thermodynamics is second law analysis. Such an analysis aids to discover the locations of maximum entropy generation and, thus, exergy destruction then to recognize the components that are responsible for the highest losses in the system [2].

All studies approved that desalination technologies have a total exergy efficiency less than 30 $\%$, multi-stage flash desalination type is considered the lowest exergy efficiency amongst the desalination technologies, its energy efficiency fluctuates between $1.8 \%-7.73 \%$. Papers available in exergy desalination field are not much due to the shortage of the data and complexity of exergy estimation of the seawater streams [3]. Osman A. Hamed et al. showed that second law simulation papers revealed that exergy destruction of the MSF distillers varied between 16.7 to $23.6 \mathrm{kWh} / \mathrm{m}^{3}$ compared to the others of only $2 \mathrm{kWh} / \mathrm{m}^{3}$ of an ideal reversible process. So, it has been recommended that hard work researches are to be done to decrease the energy consumption of the MSF distiller.

The second law of thermodynamics (exergy analysis) becomes further appreciated to measure the performance of the desalination systems. Exergy analysis interprets for the obtainable forms of energy in the system streams and energy supply with a reference environment and recognizes the major losses of energy/exergy destruction. This helps in evolving an effective desalination processes by reducing the hidden losses [4].

The exergy analysis is principally derived from second law of thermodynamics and provides a perfect basis of the inefficiencies of a MSF desalination plant. The aim of this paper is to make an exergy analysis, exergetic efficiency, and exergy destruction of MSF-BM desalination plant. The analysis is performed for the plant based on the available operating data.

\section{Plant Description}

The MSF desalination plant has been erected in Tajoura $30 \mathrm{~km}$ north-west of Tripoli the capital of Libya. The plant contains 12 stages and designed to produce $1200 \mathrm{~m}^{3} /$ day of distillate water [2]. Figure 1 shows the schematic diagram of the plant. The feed seawater is pretreated with antiscalant, antifoam chemicals and sodium-bisulfite to remove residual chlorine, then, it passes through the tube bundle of the stage 12, to increase the feed seawater temperature further until it reaches the brine heater inlet temperature $\left(98.6^{\circ} \mathrm{C}\right)$, after passing through the brine heater, the feed water reaches the top brine temperature $\left(108{ }^{\circ} \mathrm{C}\right)$ using outside heating steam supplied by an external boiler at a temperature of $115^{\circ} \mathrm{C}$. The heated feed seawater goes into the first distilling chamber and flashes to a vapor pass through a wire mesh called a demister to trap the entrained droplets and the vapor condenses over the tube bundle and collected on trays as a distilled water, the same thing happens in each stage. The

Proceedings of First Conference for Engineering Sciences and Technology (CEST-2018), vol. 2 
Exergy Analysis of a Brine Mixing Once - Through MSF-BM Distillation Plant

produced distillates in each stage are collected in an external distillate pipe and then discharged out of the plant using a distillate pump. The outstanding concentrated feed seawater is discharged out of the plant through the blow down pump. Due to the summer/winter fluctuations of the seawater temperature $\left(\min 15^{\circ} \mathrm{C} / \max 28^{\circ} \mathrm{C}\right)$, the plant is provided with an automatic remixing device, which saves the inlet temperature of the feed seawater at $28{ }^{\circ} \mathrm{C}$ [5].

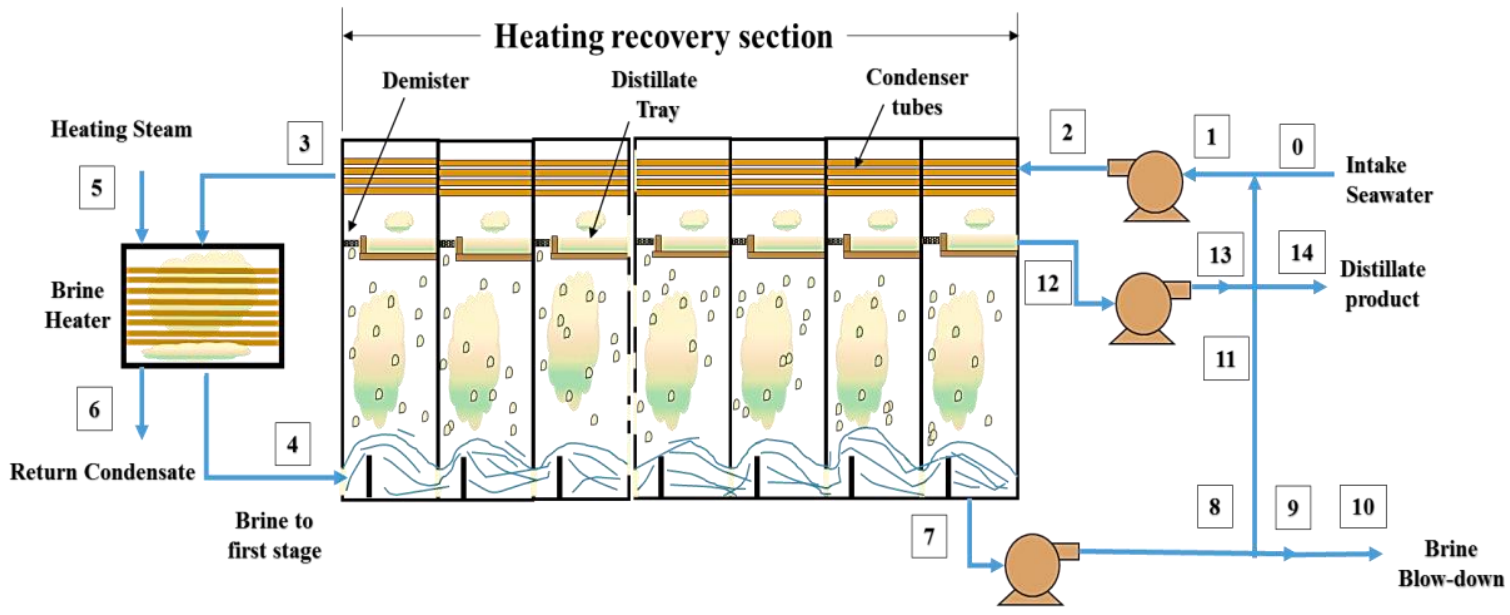

Figure 1: Schematic of the MSF-BM distillation plant.

\section{$3 \quad$ Exergy Analysis}

This once through MSF desalination plant was analysed under the following assumptions without losing accuracy, to simplify the model and make the distillation process shown in Figure 1 an idealized distillation process:

- All components of the system are assumed time-invariant (steady state) with negligible potential and kinetic energy effects.

- The reference state temperature and pressure are the temperature of the feed seawater and $1 \mathrm{~atm}$, respectively.

- The salinity of the incoming raw water is constant.

- Distillate product is salt free.

- The saline water or the mixture of salt and water is an ideal solution so the mixture properties are the average of component properties.

- Saline water, which consists of salt and water, is incompressible constituents.

- Thermodynamic properties of seawater are taken as that for sodium chloride solutions, since the latter is the primary constituent (80-90\%) in seawater.

- The impact of chemical exergy to total exergy is minor and insignificant.

- The flashing chambers and other system components are assumed to have negligible heat losses. 
The properties of seawater depend on its pressure, temperature and salinity. The later can be defined as ppm (parts per million on a mass basis), percentage (sal), salt mass fraction $\left(\mathrm{mf}_{\mathrm{s}}\right.$ ) or a salt mole fraction $\left(\mathrm{x}_{\mathrm{s}}\right) \cdot \mathrm{mf}_{\mathrm{s}}$ and $\mathrm{x}_{\mathrm{s}}$ are described as $[4,5]$ :

$m f_{s}=\frac{m_{s}}{M_{m}}=\frac{N_{S} M_{s}}{N_{m M_{m}}}=x_{s} \frac{M_{s}}{M_{m}}$ and $M f_{w}=\frac{M_{w}}{M_{m}}=x_{w}$

where $\mathrm{m}$ is mass, $\mathrm{M}$ is the molar mass, $\mathrm{N}$ is the number of moles, and $\mathrm{x}$ is the mole fraction. The letters s, w, and $\mathrm{m}$ stands for salt, water, and seawater, respectively [6].

The molar mass of the seawater is

$$
M_{m}=\frac{m_{m}}{N_{m}}=\frac{N_{s} M_{s}+N_{w} M_{w}}{N_{m}}=x_{s} M_{s}+x_{w} M_{w}
$$

The molar masses of $\mathrm{NaCl}$ and water are $58.5 \mathrm{~kg} / \mathrm{kmol}$ and $18.0 \mathrm{~kg} / \mathrm{kmol}$, respectively [6].

Mass fractions are used for salinity calculations, where mole fraction used for the minimum work calculations. Combining equations 1 and 2 and noting that $x_{\mathrm{s}}+\mathrm{x}_{\mathrm{w}}=1$ gives the following relations:

$x_{s}=\frac{M_{w}}{M_{s}\left(1 / m f_{s}^{-1}\right)+M}$ and $x_{w}=\frac{M_{s}}{M_{w}\left(1 / m f_{w}-1\right)+M_{s}}$

Solutions that have a concentration less than $5 \%$ are considered dilute solutions that behave as an ideal solution, so the effect of unlike molecules are neglected. Seawaters and saline underground waters are all ideal solutions since they have about a 4\% salinity $[4,5]$.

The enthalpy and entropy of a mixture are determined from

$H=\sum m_{i} h_{i}=m_{s} h_{s}+m_{w} h_{w} \quad$ and $\quad S=\sum m_{i} s_{i}=m_{s} s_{s}+m_{w} s_{w}$

Dividing by the total mass of the mixture gives the quantities per unit mass of mixture

$H=\sum m_{i} h_{i}=m_{s} h_{s}+m f_{w} h_{w} \quad$ and $\quad S=\sum m f_{i} s_{i}=m f_{s} s_{s}+m f_{w} s_{w}$

During mixing, no heat is released or absorbed that means the enthalpy of mixing and the mixture of an ideal gas is zero (and thus the enthalpies of its single constituents). Consequently, the enthalpy of an ideal mixture at a defined temperature and pressure is the summation of the enthalpies of its single constituents at the same temperature and pressure [7], then, it follows that the enthalpy of a seawater which can be determined from the relation above by evaluating the enthalpies of individual components at the mixture temperature and pressure. The feed seawater to the desalination plant is at about $15^{\circ} \mathrm{C}, 1 \mathrm{bar}$, and a salinity of 40,000 $\mathrm{ppm}$, these condition can be taken as a conditions of the environment, then the properties at the dead state become $\mathrm{T}_{0}=298.15^{\circ} \mathrm{K}, \mathrm{P}_{0}=1 \mathrm{bar}=101.325 \mathrm{kPa}$; salinity $=40,000 \mathrm{ppm}=4$ $\%$. 
Exergy Analysis of a Brine Mixing Once - Through MSF-BM Distillation Plant

\section{$4 \quad$ Enthalpy and Entropy of Pure Water and Salt}

Properties of pure water are available in arranged tables or computer programs. Water properties expected by the built-in functions of the Engineering Equation Solver (EES) software at temperature and pressure were used [6]. Furthermore, the equations 6 and 7 can be used for calculating enthalpy and entropy, respectively for pure water properties and provide a very close values to that achieved by EES software [6].

$h_{W}=141.355+4202.07 * t-0.535 * t^{2}+0.004 * t^{3}$

$s_{W}=0.1543+15.383^{*} t-2.996 * t^{2}+8.193 * t^{3}-1.370 * 10^{-7} * 4$

The reference state of salt is taken at $0^{\circ} \mathrm{C}$, so the enthalpy and entropy of salt at temperature $\mathrm{T}$ can be estimated by following equation

$h_{s}=h_{s o}+C_{p s}\left(T-T_{o}\right) \quad$ and $\quad h_{s}=h_{s o}+C_{p s} \ln \left(T / T_{o}\right)$

The specific heat of salt $C_{\mathrm{ps}}=0.8368 \mathrm{~kJ} / \mathrm{kg} .{ }^{\circ} \mathrm{K}$. The enthalpy and entropy of salt at $\mathrm{T}_{\mathrm{o}}=15^{\circ} \mathrm{C}$ $\mathrm{h}_{\text {so }}=12.552 \mathrm{~kJ} / \mathrm{kg}$ and $\mathrm{s}_{\mathrm{so}}=0.04473 \mathrm{~kJ} / \mathrm{kg} .{ }^{\circ} \mathrm{K}$, respectively (The enthalpy and entropy of incompressible constituents are independent of pressure) [4].

The entropy of each constituent in an ideal solution at a defined temperature $\mathrm{T}$ and pressure $\mathrm{P}$ is

$\bar{S}_{i}=S_{i, p u r e}(T, \bar{P})-R_{u} \ln x_{i}$

Then the entropy of a saline solution (salt and water) is

$\overline{\mathrm{S}}=\mathrm{x}_{\mathrm{S}}^{-}{ }_{\mathrm{S}}^{-}+\mathrm{x}_{\mathrm{wS}}^{-}=\mathrm{x}_{\mathrm{s}}\left[\overline{\mathrm{S}}_{\mathrm{s}, \text { pure }}(\mathrm{T}, \mathrm{P})-\mathrm{R}_{\mathrm{u}} \ln \mathrm{x}_{\mathrm{s}}\right]+\mathrm{x}_{\mathrm{w}}\left[\overline{\mathrm{S}}_{\mathrm{w}, \text { pure }}(\mathrm{T}, \mathrm{P})-\mathrm{R}_{\mathrm{u}} \ln \mathrm{x}_{\mathrm{w}}\right]=$ $x_{x} \bar{S}_{s, p u r e}(T, P)-R_{u}\left(x_{s} \ln x_{s}+x_{w} \ln x_{w}\right)$

The entropy of saline water per unit mass is estimated by dividing by the molar mass of saline water. So the equation 10 can be written as:

$\mathrm{S}=\mathrm{mf}_{\mathrm{s}} \mathrm{s}_{\mathrm{s}, \text { pure }}(\mathrm{T}, \mathrm{P})+\mathrm{mf}_{\mathrm{w}} \mathrm{s}_{\mathrm{w}, \text { pure }}(\mathrm{T}, \mathrm{P})-\mathrm{R}_{\mathrm{m}}\left(\mathrm{x}_{\mathrm{s}} \ln \mathrm{x}_{\mathrm{s}}+\mathrm{x}_{\mathrm{w}} \ln \mathrm{x}_{\mathrm{w}}\right)\left(\mathrm{kJ} / \mathrm{kg} .{ }^{\circ} \mathrm{K}\right)$

The specific exergy of each stream is given by

$\Psi=h-h_{o}+T_{o}\left(S-S_{o}\right)$

Then the exergy flow rate related becomes

$\dot{X}=\dot{m} \Psi=\dot{m}\left[h-h_{o}+T_{o}\left(S-S_{o}\right)\right]$

By means of the previous equations, the specific exergy and exergy flow rates at different locations shown in Figure 1 are estimated. 
The overall exergy balance for any system can be expressed as [8].

$X_{\text {in }}=X_{\text {out }}-X_{\text {destroyed }}=\Delta \mathrm{X}_{\text {system }}$

If there is no work interaction (adiabatic steady sate system), the earlier equation can be simplified to

$X_{\text {destroyed }}=X_{\text {in }}-X_{\text {out }}$

The exergy efficiency of all constituents can be estimated by

$\eta_{c}=1-X_{\text {destroyed }} / X_{\text {out }}$

\section{$5 \quad$ Results and Discussion}

Tajoura desalination plant was analysed using the relations prescribed above, where the specific exergy, the exergy flow rates and the rate of exergy change at different locations are calculated, and the results are tabulated in Table 1. The locations of the states are illustrated in the diagram of Tajoura plant shown in Figure 1. The feed seawater enters the plant and the final permeate and concentrate leaving the plant are at the same dead state temperature and pressure, but at different salinities. Thus, the exergies of the concentrate line differ only due to the change in salinities, as it can be seen from Table 1 the raw feed seawater at state 0 has zero exergy since it is at the dead state. The brine at state 10 leaves the system at a high salinity of 58,700 ppm.

The results of the analysis are obtained using the EES software and are given in Table 1. Saline water is heated from $\left(98.61{ }^{\circ} \mathrm{C}\right) 371.76{ }^{\circ} \mathrm{K}$ to $\left(108{ }^{\circ} \mathrm{C}\right) 381.15^{\circ} \mathrm{K}$ at a rate of $3621 \mathrm{~kg} / \mathrm{s}$ by super-heated steam at $179.91{ }^{\circ} \mathrm{C}$ in a heat exchanger. Steam leaves the heat exchanger at the same temperature as saturated liquid. An energy balance on the heat exchanger gives the condensation rate of steam to be $2.06 \mathrm{~kg} / \mathrm{s}$, where the heat transfer rate to the saline water from steam is

$$
\dot{Q}_{\text {in }, \text { steam }}=\dot{m}_{\text {steam }} h_{f g}=4142.36 \mathrm{~kJ} / \mathrm{s}
$$

Taking the dead state temperature to be To $288.15 \circ \mathrm{K}$, the rate of exergy supply by the steam is

$$
\begin{gathered}
\dot{X}_{\text {in,steam }}=\dot{m}_{\text {steam }}\left(\Delta h-T_{o} \Delta s\right) \text { or } \dot{m}_{\text {steam }}\left(h_{f g}-T_{o} T s_{f g}\right) \\
\dot{X}_{\text {in,steam }}=1508.36 \mathrm{~kJ} / \mathrm{s}
\end{gathered}
$$

The total exergy rate is the sum of the exergy variations through the pumps and can be expressed as

$$
\Delta \dot{X}_{\text {pumps }}=\Delta \dot{X}_{\text {seawater pump }}+\Delta \dot{X}_{\text {distillate pump }}+\Delta \dot{X}_{\text {brine blowdown pump }}
$$




$$
=\left(\dot{X}_{2}-\dot{X}_{1}\right)+\left(\dot{X}_{8}-\dot{X}_{7}\right)+\left(\dot{X}_{13}-\dot{X}_{12}\right)=9085.24 k W
$$

For a combined pump-motor efficiency of $79 \%$, the exergy supplied in the form of electric power is

$$
\dot{X}_{\text {in }, \text { pumps }}=\frac{\Delta \dot{X}_{\text {pumps }}}{\eta_{\text {ump-motor }}}=11500.30 \mathrm{~kW}
$$

Where, a combined pump-motor efficiency can be expressed as the ratio of the mechanical energy transferred to the fluid over the electrical energy consumed [7].

$$
\dot{X}_{\text {in, total }}=\dot{X}_{\text {in, steam }}+\dot{X}_{\text {in, pumps }}=13008.67 \mathrm{~kW}
$$

Table 1: Properties and exergy flow rates at various locations all over the plant.

\begin{tabular}{|l|l|l|l|l|l|l|}
\hline $\begin{array}{l}\text { Locatio } \\
\mathrm{n}\end{array}$ & $\begin{array}{l}\text { Temperature } \\
\text { T, oK }\end{array}$ & $\begin{array}{l}\text { Pressur } \\
\mathrm{e} \\
\mathrm{P}, \mathrm{kPa}\end{array}$ & $\begin{array}{l}\text { Salinity } \\
\mathrm{ppm}\end{array}$ & $\begin{array}{l}\text { Mass flow } \\
\text { rate, } \mathrm{kg} / \mathrm{s}\end{array}$ & $\begin{array}{l}\text { Specific exergy } \\
\psi, \mathrm{kJ} / \mathrm{kg}\end{array}$ & $\begin{array}{l}\text { Exergy flow } \\
\text { rate, }, \dot{\mathrm{X}}, \mathrm{kW}\end{array}$ \\
\hline 0 & 288.15 & 101.325 & 40,000 & 52.58 & 0.00 & 0.00 \\
\hline 1 & 301.15 & 281.325 & 52,100 & 123.12 & 25.4365 & 3131.801 \\
\hline 2 & 301.15 & 700 & 52,100 & 123.12 & 4.291 & 7915.647 \\
\hline 3 & 371.73 & 700 & 52,100 & 123.12 & 102.929 & 12672.882 \\
\hline 4 & 381.15 & 700 & 52,100 & 123.12 & 111.66 & 13747.794 \\
\hline 5 & 453.06 & 1000 & - & 2.06 & 733.797 & 1508.360 \\
\hline 6 & 453.06 & 1000 & - & 2.06 & 0.000 & 0.000 \\
\hline 7 & 310.57 & 101.325 & 58,700 & 123.12 & 9.60737 & 1182.881 \\
\hline 8 & 310.57 & 180 & 58,700 & 123.12 & 16.8889 & 2079.402 \\
\hline 9 & 310.57 & 180 & 58,700 & 52.58 & 16.8889 & 888.076 \\
\hline 10 & 288.15 & 101.325 & 58,700 & 52.58 & 9.56663 & 503.045 \\
\hline 11 & 310.57 & 180 & 58,700 & 70.54 & 16.8889 & 1191.326 \\
\hline 12 & 310.57 & 101.325 & 1 & 13.89 & 22.2146 & 308.537 \\
\hline 13 & 310.57 & 300 & 1 & 13.89 & 41.8758 & 581.608 \\
\hline
\end{tabular}

The minimum work requirement to extract product water with a mass flow rate of $51.25 \mathrm{~kg} / \mathrm{s}$ from the incoming seawater with a salinity of $40,000 \mathrm{ppm}$ at $15{ }^{\circ} \mathrm{C}, 1 \mathrm{~atm}$ into $13.89 \mathrm{~kg} / \mathrm{s}$ of fresh water with zero salinity and $29.67 \mathrm{~kg} / \mathrm{s}$ of concentrate water with a salinity of 58,700 $\mathrm{ppm}$ at the same temperature and pressure. The minimum work input for a steady flow adiabatic process is the work input required for a reversible adiabatic process and is equivalent to the variance between the leaving exergy streams and the entering exergy streams, plus the salinity exergy [8]. Where, the inlet and exit streams are at the same temperature and pressure, 
and thus, this work is totally due to the composition of the entering and leaving streams. Therefore

$$
\dot{W}_{\text {min }}=\dot{X}_{\text {outgoing brine and product water }}-\dot{X}_{\text {incoming seawater }}=\dot{X}_{14}+\dot{X}_{10} \dot{X}_{0}=811.58 \mathrm{~kW}
$$

The second-law efficiency is a degree of the process approximation to a reversible process, and it specifies the range accessible for potential improvements, noting that the second-law efficiency ranges from 0 for a totally irreversible process to 100 percent for a totally reversible process [9], the second law efficiency of the plant is the ratio of the minimum required inlet exergy to the total actual exergy, which can be expressed as

$$
\dot{X}_{I I}=\frac{\dot{X}_{\text {in, } \min }}{\dot{X}_{\text {in,total }}}=6.36 \%
$$

This value indicates that this MSF plant at the specified rates could be accomplished using only $811.58 \mathrm{~kW}$ of exergy (or work input) instead of $13008.67 \mathrm{~kW}$. Then, the total exergy destruction becomes

$$
\dot{X}_{\text {destroyed,total }}=\dot{X}_{\text {in,total }}-\dot{X}_{\text {in,min }}=\dot{X}_{\text {in,total }}-\dot{W}_{\text {min }}=12197.08 \mathrm{~kW}
$$

The real value of second law analysis becomes more evident when the analysis is performed at the component level, and the sites of maximum exergy destruction upto the smallest exergy destruction are calculated according to following exergy balance equations:

$$
\dot{X}_{\text {destroyed,pumps }}=\dot{X}_{\text {in,pumps }}-\Delta X_{\text {pumps }}=2415.06 \mathrm{~kW}(19.8 \% \text { of total })
$$

The exergy balance for any system undergoing any process is expressed as:

$$
X_{\text {in }}-X_{\text {out }}-X_{\text {destroyed }}=\Delta X_{\text {system }}
$$

For adiabatic steady state system, which has no energy transfer by work and no change in exergy, the relation above can be simplified to

$$
\dot{X}_{\text {destroyed }}=X_{\text {in, by mass }}-\dot{X}_{\text {out, by mass }}
$$

The exergy destruction fraction within a component is determined from

$$
f_{\text {Destroyed }} \frac{\dot{X}_{\text {destroyed,component }}}{\dot{X}_{\text {destroyed, total }}}=\frac{\dot{X}_{\text {destroyed,component }}}{12197.08 \mathrm{~kW}}
$$

The amounts and fractions of exergy destroyed in the various components are determined to be as follows:

For the MSF unit:

$$
\begin{gathered}
\dot{X}_{\text {destroyed,MSF }}=\left(\dot{X}_{2}+\dot{X}_{4}\right)-\left(\dot{X}_{3}+\dot{X}_{7}+\dot{X}_{12}\right) \\
\dot{X}_{\text {destroyed }, M S F}=7499.14 \mathrm{~kW}(61.48 \%)
\end{gathered}
$$


Exergy Analysis of a Brine Mixing Once - Through MSF-BM Distillation Plant

For the steam-brine HX:

$$
\dot{X}_{\text {brine } H X}=\left(\dot{X}_{3}+\dot{X}_{5}\right)-\left(\dot{X}_{4}+\dot{X}_{6}\right)=433.45(3.56 \%)
$$

For the mixing point:

$$
\dot{X}_{\text {destroyed, mixer }}=\dot{X}_{O}+\dot{X}_{11}-\dot{X}_{1}=-1940.47 \mathrm{~kW}(15.9 \%)
$$

For the discharged brine:

$$
\dot{X}_{\text {destroyed, brine }}=\dot{X}_{9}-\dot{X}_{10}=385.03 \mathrm{~kW}(3.16 \%)
$$

For the product water:

$$
\dot{X}_{\text {destroyed, } \text { product }}=\dot{X}_{13}-\dot{X}_{14}=273.07 \mathrm{~kW}(2.24 \%)
$$

The exergy analyses were conducted to obtain that the largest exergy destruction about 61.48 $\%$ of the total exergy input occurs within the MSF unit, followed by the next largest exergy destructions occur in the pumps and their motors $19.8 \%$, and the heat exchanger $3.56 \%$. The remaining exergy destruction are $3.16 \%$ and $2.24 \%$ of total exergy happens at the brine and product streams, respectively. The locations of the above stated amounts and percentages are shown in Figure 2.

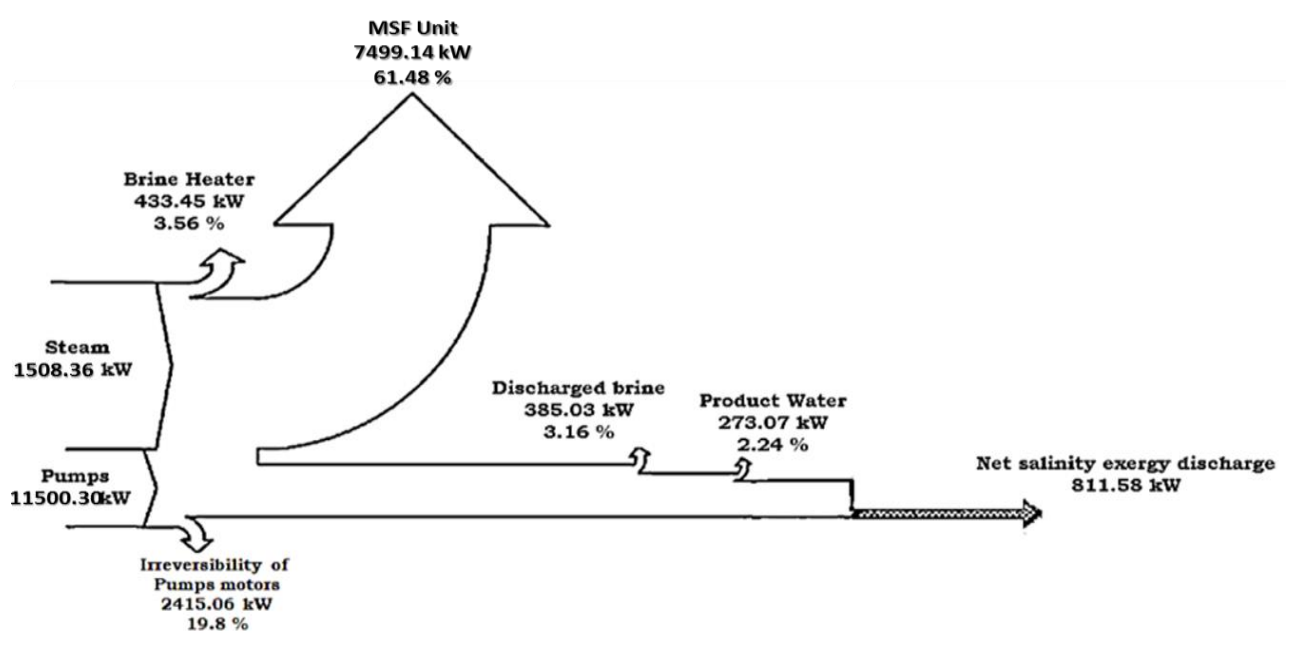

Figure 2: Exergy flow diagram with exergy destruction amount and percentages.

\section{Conclusion}

In conclusion, exergy analysis was found cooperative and significant tool for investigating the MSF-BM desalination plant from the vision of optimum usage of energy and must be taken into consideration at preliminary steps of design. Furthermore, it is shown that second-law efficiency (exergetic efficiency) is a valuable tool for a decision-maker to optimize the performance of different designs, where the second law efficiency was evaluated to be $6.24 \%$, which is very low, in reality the second law efficiency of a modern power plant is over $50 \%$. Therefore, it offers a potential for performance improvement. The exergy analysis shows that, 
the highest exergy destruction was $61.48 \%$ that occurs in MSF chambers followed by the pumping motor with $19.8 \%$ of the total input exergy that means some modifications for performance improvement can be considered according to the modern designs, as well as high efficient motors can be used to increase the second law efficiency. Moreover, an important exergy savings can be achieved by using hybrid designs. Additionally, the heat loss by the power plants can be used as heat source for generating the steam for the brine heater to enhance the performance of the desalination plants.

\section{References}

[1] K. Wangnick, 1998 IDA Worldwide Desalination Plants Inventory, Wangnick Consulting, in cooperation with IDA, IDA Report No. 16, 2000.

[2] O. Hamed, Thermal performance of multi stage flash distillation plants in Saudi Arabia, Al Jubail plant and others. Desalination 2000; 128:281-92.

[3] M. Al-Weshahi, A. Anderson, G. Tian, Exergy Efficiency Enhancement of MSF Desalination by Heat Recovery from Hot Distillate Water Stages.

[4] U. Ezzeghni, M. El-bourawi, Exergy analysis of a 10,000 $\mathrm{m}^{3} /$ day Tajoura SWRO desalination plant, The 1st International Conference on Chemical, Petroleum, and Gas Engineering (ICCPGE 2016) 20th - 22th December 2016, Alkhoms-Libya.

[5] G. Gude, N. Nirmalakhandan, S. Deng, A. Maganti, Desalination at low temperatures: An exergy analysis. Desalin. Water Treat. 2012, 40, 272-281.

[6] M. Abduljawad, U. Ezzeghni, Optimization of Tajoura MSF desalination plant, Desalination 254 (2010) 23-28.

[7] N. Kahraman and Y.A. Cengel, Exergy analysis of a MSF distillation plant, Energy Conv. Mgmt., 46 (2005) 26252636.

[8] N. Kahraman, Y. Cengel, B. Wood and Y. Cerci, a combined RO, NF, and EDR desalination plant. Desalination, 171 (2004) 217-232.

[9] Improving the thermodynamic and economic efficiencies of desalination plants: Minimum work required for desalination and case studies of four working plants. Desalination and water purification research and development program final report No. 78, U.S. Department of the interior, November 2003. 